Case Report

\title{
Endodontic treatment of a maxillary central incisor with three root canals
}

\author{
Mahshid Sheikh-Nezami ${ }^{1)}$ and Nima Mokhber ${ }^{2)}$ \\ ${ }^{1)}$ Department of Endodontics, Faculty of Dentistry and Dental Research Center, \\ Mashhad University of Medical Sciences, Mashhad, Iran \\ ${ }^{2}$ Department of Orthodontics, Faculty of Dentistry and Dental Research Center, \\ Mashhad University of Medical Sciences, Mashhad, Iran
}

(Received 16 January and accepted 19 June 2007)

\begin{abstract}
Abnormal morphology of the root canal may exist in any tooth, even a maxillary central incisor. In this paper we report endodontic treatment for a rare example of a maxillary central incisor with one root and three root canals. (J. Oral Sci. 49, 245-247, 2007)
\end{abstract}

Keywords: maxillary central incisor; three root canals.

\section{Introduction}

The presence of an additional root canal in the maxillary central incisor is extremely rare. A number of studies of root canal anatomy have described that the maxillary central incisor has only one root and one canal in 100\% of examined cases (1-4), with variations only in the number of lateral canals and the position of the apical foramen.

Some clinical reports have described a maxillary central incisor with two canals or two roots (5-14). Only one report has described endodontic treatment of a very unusual maxillary central incisor that had dens invagination and four canals (15). Here we report the features and endodontic therapy of a very rare example of a maxillary central incisor with three canals in a single root.

\section{Case Report and Results}

An 11-year-old male patient without any remarkable medical history was referred to the Department of Endodontics, Faculty of Dentistry, Mashhad, Iran. His

Correspondence to Dr. Mahshid Sheikh-Nezami, Faculty of Dentistry and Dental Research Center, Mashhad University of Medical Sciences, Vakilabad Blvd, Mashhad, Iran

Tel: +98-511-8829501-15

Fax: +98-511-8829500

E-mail: m_sh_nezami@yahoo.com maxillary right central incisor had suffered a traumatic complicated crown fracture 2 weeks previously. Clinical examination revealed that approximately $3 \mathrm{~mm}$ of the incisal edge of the tooth had been broken horizontally. There was spontaneous and severe pain due to cold, heat, and mastication, and the tooth was also tender to percussion and palpation. However, there was no mobility or crown discoloration and the pocket depth was normal. The adjacent teeth gave normal responses to cold, heat, and electrical stimulation of the pulp, percussion, palpation and mobility tests. Radiographic examination showed one root and three root canals that converged in the apical third with no periapical changes (Fig. 1). This anatomical variation of the root canal was also evident in the patient's other maxillary incisors.

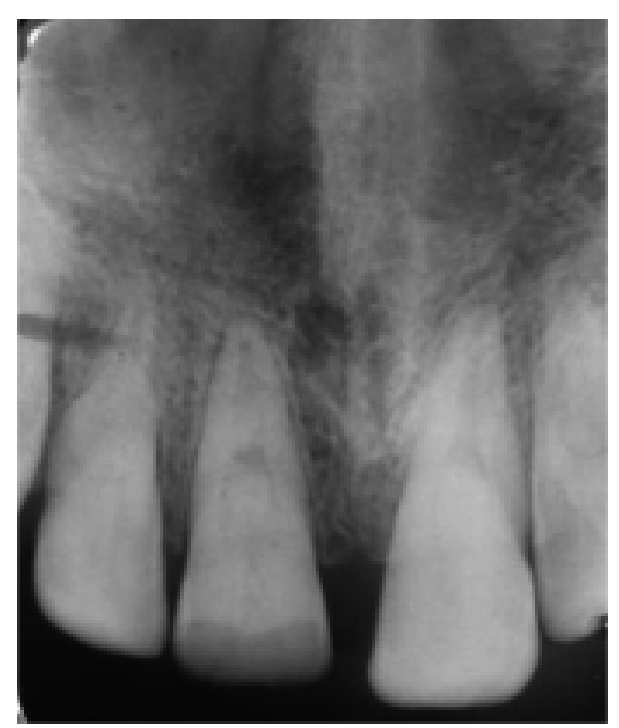

Fig. 1 Preoperative diagnostic radiograph showing one root and 3 root canals. 
In this case, care was necessary for preparation of the access cavity because of the unusual pulp chamber anatomy in order to locate orifices under local anesthesia and rubber dam isolation. The major canal in the center of the root was immediately located after removing the roof of the pulp chamber. However, the thin orifices of the mesiobuccal and distobuccal canals were pinpointed through extended access toward the buccal side, removal of excess dentin in the the operation area, and by means of a CK-17 endodontic explorer. Thereafter, the three canals were negotiated using a No.8 K-file (Maillefer, Ballaigues, Switzerland), and working length was established using a No.15 K-file (Maillefer) (Figs. 2, 3). A rubber dam was placed on the left central incisor, in order to prevent superimposition of canals in the coronal third of the root. Then instrumentation was done using a step-back technique up to a No. 70 K-file (Maillefer), Gates-Gliddens No. 2, 3 (Maillefer), and copious irrigation with $2.6 \%$ sodium hypochlorite. Cleaning and shaping were completed and

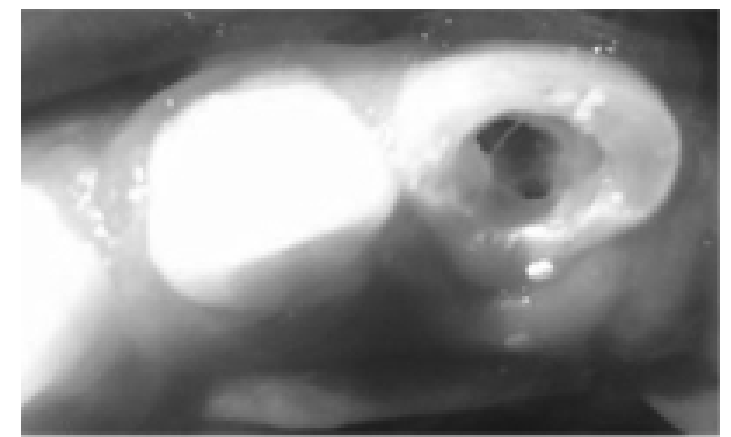

Fig. 2 Clinical view of the pulp chamber and orifices. obturation was performed using a lateral condensation technique with gutta-percha and AH26 sealer (Dentsply, De Trey, Germany) (Fig. 4). Zonalin dressing (Masterdent, NY, USA) was applied as a temporary restoration of the access cavity. Final restoration of the tooth was accomplished using composite resin (Synergy, Coltene, Langenau, Germany) after one week.

\section{Discussion}

Root canal anomalies, usually those caused by fusion or gemination, are revealed when coronal anomalies occur.

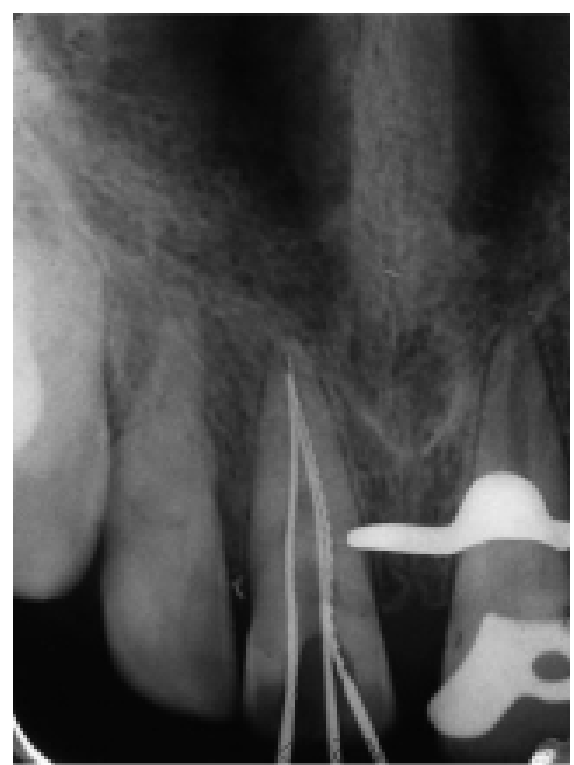

Fig. 3 Determination of working length with a periapical radiograph.
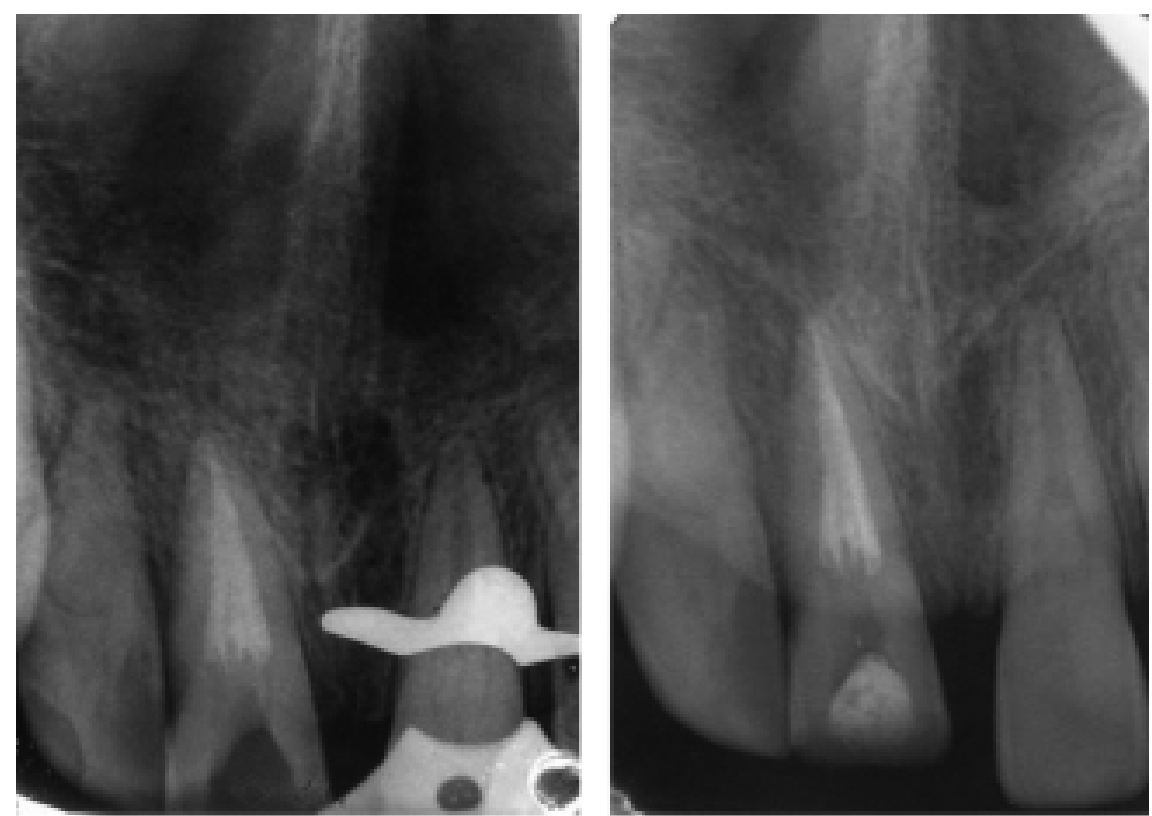

Fig. 4 Obturation of the canals with gutta-percha. 
However, some teeth with clinically normal crowns can have root canal anomalies.

In cases of fusion of two adjoining tooth germs during development there is one less tooth than normal in the affected dental arch. Alternatively, an abnormal tooth can fuse with a supernumerary tooth, in which case the number of teeth remains normal and diagnosis is easy because the supernumerary tooth is often atypical. There may be a common root canal or entirely separate root canals depending on whether fusion occurs during very early tooth formation or later. Germination is the attempted division of a single tooth germ by invagination during the growth cycle. The number of teeth is normal. Division is usually incomplete and the result is two completely or incompletely separate crowns with a single root and root canal space, the crowns of which are wider than normal and often have a vertical incisogingival groove (11).

In the present case, the size of the tooth crown in comparison with its adjacent teeth was normal. Also, there were a normal number of teeth in the dental arch.

Although the maxillary central incisor usually has one canal, clinicians need to be aware of unexpected root canal morphology when performing root canal therapy. Obviously, a knowledge of pulp anatomy (knowing where to look for, and expect to find, the orifices), perseverance and care are necessary for access cavity preparation and location of the canal orifices, along with magnification and adequate illumination to reveal color changes in the internal dentin and subtle landmarks that may not be visible to the unaided eye. Surgical loupes, endodontic endoscopes and dental operating microscopes are some of the commercially available instruments that can help the clinician to accomplish these goals. In cases of greatly receded pulp, the use of extended shank round burs even in a miniature handpiece will extend the depth of cut to find a thin orifice. It is most important to enlarge the occlusal opening so that complete control over the direction of the instrument can be maintained. Repeated radiographs to verify the depth and direction of the cut are also valuable.

\section{Acknowledgments}

This paper has been prepared with the cooperation of ACECR-Mashhad Branch.

\section{References}

1. Kerekes K, Tronstad L (1977) Morphometric observations on root canals of human anterior teeth. J Endod 3, 24-29

2. Vertucci FJ (1984) Root canal anatomy of the human permanent teeth. Oral Surg Oral Med Oral Pathol $58,589-599$

3. Teo CS, Chan NC, Loh HS (1988) The position of the apical foramen of the permanent incisors. Aust Dent J 33, 51-55

4. Kasahara E, Yasuda E, Yamamoto A, Anzai M (1990) Root canal system of the maxillary central incisor. J Endod 16, 158-161

5. Sponchiado EC Jr, Ismail HA, Braga MR, de Cavalho FK, Simoes CA (2006) Maxillary central incisor with two root canals: a case report. J Endod 32, 1002-1004

6. Mehlman ES (1978) Management of a totally fused central and lateral incisor with internal resorption perforating the lateral aspect of the root. J Endod 4, 189-191

7. Mader CL, Konzelman JL (1980) Double-rooted maxillary central incisor. Oral Surg Oral Med Oral Pathol 50, 99

8. Sinai IH, Lustbader S (1984) A dual-rooted maxillary central incisor. J Endod 10, 105-106

9. Hosomi T, Yoshikawa M, Yaoi M, Sakiyama Y, Toda T (1989) A maxillary central incisor having two root canals geminated with a supernumerary tooth. J Endod 15, 161-163

10. Michanowicz AE, Michanowicz JP, Ardila J, Posada A (1990) Apical surgery on a two rooted maxillary central incisor. J Endod 16, 454-455

11. al-Nazhan S (1991) Two root canals in a maxillary central incisor with enamel hypoplasia. J Endod $17,469-471$

12. Lambruschini GM, Camps J (1993) A two-rooted maxillary central incisor with a normal clinical crown. J Endod 19, 95-96

13. Genovese FR, Marsico EM (2003) Maxillary central incisor with two roots: a case report. J Endod 29, 220-221

14. Gonzalez-Plata-R R, Gonzalez-Plata-E W (2003) Conventional and surgical treatment of a two rooted maxillary central incisor. J Endod 29, 422-424

15. Mangani F, Ruddle CJ (1994) Endodontic treatment of a "very particular" maxillary central incisor. J Endod 20, 560-561 